\title{
EFFECTIVENESS OF DIAGNOSIS BASED REMEDIATION ON ATTAINMENT OF MLL IN MATHEMATICS AMONG V STANDARD STUDENTS
}

\section{Prakash K.* \& Premalatha Sharma**}

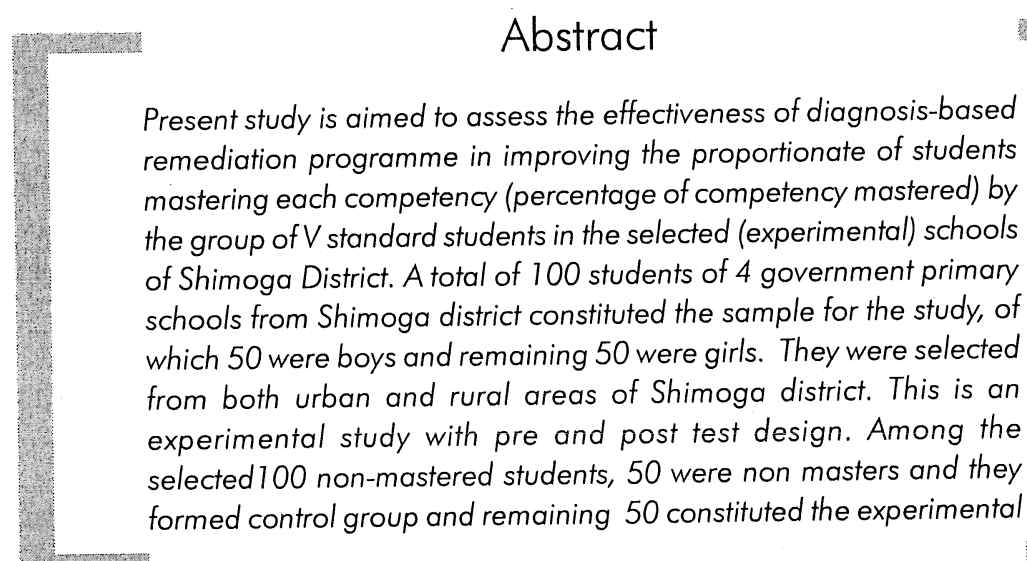

f

* National College of Education, Balaraja Urs Road, Shimoga, Karnataka(s), India. Email: prakashriem@gmail.com

** Department of Education, Regional Institute of Education, Manasagangothri, Mysore,Karnataka(s),India-570 006. Email: dr.pl.sharma@gmail.com 
group. After 2 months of intervention for the experimental group, the investigator conducied post test for both controlled and experimental groups. The controlled group students were attending regular classes whereas students from experimental group were attending the intervention class outside the class room which was taken by the investigator himself. MLL based test developed by Kashinath (2005) was adapted and used for assessing selected MLL competencies, which had 7 competencies was administered on the students selected 4 government primary schools of Shimoga district. The results showed that experimental group had gained significantly higher competencies in total scores than the control group. Further, male students of experimental group had substantial gain compared to all other groups.

Key words: MLL, attainment, mathematics, shimoga

\section{Introduction}

Mathematics plays an important role in school learning and assumes a prominent position in modern education and curriculum. In the past, aim of mathematics in the school curriculum was to prepare children for the life to enable them to use mathematics in the everyday world around them. But in this century, there are several factors of life that requires us to examine a new role that mathematics education is to play in the development students for the scientific technological and industrial society. Every citizen of this complex society must understand mathematics if he/she is to comprehend the operation of Governments and the material he or she reads in newspapers. In fact not just mathematics, but also a strong foundation in mathematics is needed by almost all the disciplines. Thus in these circumstances of increased importance and influence of mathematics, just a computational knowhow of mathematics is not enough. The development of concepts and ideas of mathematics at the elementary school level is a must. Thus learning basic mathematics is a necessity in day today life and useful for continuing education in higher classes and courses.

Primary education in particular has remained a serious concern of the nation since independence. A large number of programmes and schemes have been initiated both by the Central and State Governments to realize the goal of the universalization of primary education. This has led to the opening of a large number of schools with emphasis on enrolment and retention coupled with focus on quality of education. The quantitative expansion seems to have diluted the quality of education. Research studies conducted both at national and state levels point out low level of learning 
in schools and the situation becomes worse as children move to higher classes. Poor level of achievement at primary stage is a big de-motivating factor resulting in repetition and drop out from the schools.

These levels of achievement for any nation are so important that they need to be known periodically to keep a tab on the general health of the education system. Such a requirement warrants the conduct of periodical achievement surveys at different stages of school education in order to initiate remedial measures for improving the quality of education. National Policy on Education (NPE) - 1986 recommended the conduct of periodical achievement surveys at all stages of school education. This has also been reiterated in the National Curriculum Framework for School Education-2005.

Mathematics, by and large, is taught in a stereotyped and mechanical way in schools "Experience has shown that the majority of students normally fail in Mathematics at the end of class X (NCERT, 2000). A mid term National survey on learning Achievement of class V Children (2008) states that (i) National average in Mathematics was $48.46 \%$;indicating an increase of $1.95 \%$ from Base Line Achievement measured in year 2001-02. (ii) There was no significant difference between boys and girls. In achievement however, rural children scored significantly better than their urban counterparts. Urban girls scored significantly better than urban boys. (iii) The performance of children is the poorest in Mathematics and better in Language.

The National Resource Group of SSA(2008) advised Central and State Governments on all aspects of quality improvement in elementary education, through SSA and related programmes, with special reference to Laying down of minimum levels of learning and their incorporation in curricula, textbooks and teaching process and Monitoring learner achievement vis-à-vis MLL's and action for improving attainment levels.

Generally during the remedial instruction, which is provided after the initial instruction and formative testing, the student's difficulty, patterns are detected and appropriate remediation is provided. This difficulty pattern may also include the lack of prerequisite knowledge pertaining to the content. But a delay in detecting results in students wasting their time during the initial instruction and formative testing which could otherwise have been saved if appropriate measures were taken prior to the onset of instruction. Thus diagnosis of the learner's place in the learning curve pertaining to that content is necessary before the onset of instruction. This would serve to detect what knowledge the student possesses related to that content. If the student lacks some prerequisite knowledge then appropriate remediation can be provided the instruction. 


\section{Hypotheses}

1. There is no significant difference between control and experimental group in the effect of diagnosis-based remediation programme in improving the proportionate of students mastering each competency (percentage of competency mastered) by the group of $\mathrm{V}$ standard students in the selected (experimental) schools of Shimoga District.

2. Male and female students gain equally after remediation programme in improving the competencies in mathematics

\section{Method:}

This is an experimental study with pre and post test design. In this study the investigator has selected 18 sub competencies from $V$ standard text book of mathematics. These 18 sub competencies from 7 main areas (competencies) were selected because in all the selected schools these competencies were taught in first semester. Based on these MLL competencies investigator adapted a standard test developed by Dr. H. M. Kashinath (2005). The adaptation was made in the light of competencies taught. The adapted test was also tried out on $30 \mathrm{~V}$ standard students. The test finalized by dropping the competencies which were very easy and ware very difficult. The opinion of various experts was also taken for finalizing the adapted test. The test was used as pre and post test for assessing the effectiveness of the intervention for learning non mastered competencies. The investigator also planned and developed teaching strategies for teaching each sub-competency selected. The details of these strategies have been discussed below.

The investigator used these strategies for all non-masters from experimental group. The investigator took one session in each school on alternative days for the experimental group. In this way the investigator covered all the non-mastered competencies during two months of intervention. After 2 months of intervention for the experimental group, the investigator conducted post test for both controlled and experimental groups. The controlled group students were attending regular classes whereas students from experimental group were attending the intervention class outside the class room which was taken by the investigator himself. The performance of the students from pre and post tests was analyzed to assess the effectiveness of intervention on learning. 


\section{Sample}

In order to serve the objective of the study, 4 schools out of 196 schools were randomly selected from Shimoga district. On the basis of performance on competencies included in the pre- test of Mathematics the masters and non-masters identified were listed. Those students who were found achieving less than $80 \%$ of the competencies were non-masters and they were considered for experimental group.

Tool:

\section{MLL Competency Based Test in Mathematics}

For assessing, MLL competencies taught in first semester were made as base for adapting the test which was developed by H.M. Kashinath, et: al.( 2005). The investigator confined to the competencies taught only in I semester to $V$ standard students.

Competencies covered by the Test were

i) Numbers

ii) Different numerals

iii) Fundamental operations

iv) Fractions

v) Decimals fundamental operations

vi) Decimals addition and subtraction with mixed operations

vii) Angles

\section{Reliability of the Achievement test}

"The reliability of a test or any measuring instrument depends upon the consistency with which it gauges the ability to which it is applied" (H. E. Garret, 1986). There are number of approaches to assess the reliability of a test. The choice of approach depends on the type of information one is seeking. As a test score is only interpretable when the test possesses substantial internal consistency, that is, all the items in the 
test measure the same construct, the coefficient of internal consisting would be interest (Coronbach, 1951). In this study the coefficient of internal consistency has been obtained by using the split-half method.

The test scores can be interpreted when it possesses substantial internal consistency. In this study the coefficient of internal consistency was obtained by the H. M. Kashinath, the author of original test but investigator also found out internal consistency through using the split half method.

A test is said to be internally consistent if all its items measures the same thing. To estimate the internal consistency of the test the split half method has been used. The coefficient of internal consistency has been computed for the test by finding the product moment correlation between the score on odd and even numbered sub competencies and then self correlation coefficient of the whole test has been estimated by using spearman-brown prophecy formula.

The reliability was found as 0.77 . Thus the test has a high reliability

\section{Validation of the test}

The test is valid if the scores it assigns to examinees are free from constant and systematic errors and hence the interference based on these scores were justified. The content validity of the test refers to the extent to which the test contains a representatative sample of items, which define the content domain of interest.

Copies of the this test were distributed, along with the copies of the list of competencies selected to six content specialists in mathematics education and mathematics teachers of Regional Institute of Education and Subject Inspector and experts in mathematics in Shimoga district. The experts are requesied to judge the relevance of each item in the test and to critically examine them to ascertain the adequacy and clarity of the items. Based on the opinion of the content experts, suitable modifications were made in the test.

\section{Remediation Programme}

In remedial instruction, we provide remedial alternatives matched to each of the objectives/items, so when the student makes an error in the test item, a remedial alternative is provided. This alternative may be chosen according to its suitability to the learner, e.g. if the learner prefers to learn in the programme learning style, he/ she is provided instruction in the programmed learning material (PLM) form. But 
this provision may not solve her/his difficulty in learning the concept, for here, it is not just the method that is inappropriate but, rather the diagnosis is not deep enough to spot out the source which has created the error. Hence, unnecessarily wasting time by trying out alternative ways of teaching would be ridiculous. Therefore, time could be saved if more efforts are put forth to locate the source of the error before choosing the method of presentation.

\section{Analysis of Results}

Table 2. Mean pre and post- test scores on total competency scores of male and female in experimental and control groups

\begin{tabular}{|c|c|c|c|c|c|c|}
\hline \multirow{3}{*}{ Groups } & \multirow{3}{*}{ Gender } & \multicolumn{4}{|c|}{ Sessions } & \multirow{3}{*}{$\begin{array}{c}\text { Change } \\
\text { gain }\end{array}$} \\
\hline & & \multicolumn{2}{|c|}{ Pre-test } & \multicolumn{2}{|c|}{ Post-test } & \\
\hline & & Mean & S.D. & Mean & S.D. & \\
\hline Mean & S.D & & & & & \\
\hline \multirow[t]{3}{*}{ Control } & Male & 15.27 & 2.62 & 15.50 & 2.44 & 0.23 \\
\hline & Female & 14.61 & 2.99 & 16.32 & 3.44 & 1.71 \\
\hline & Total & 14.90 & 2.82 & 15.96 & 3.04 & 1.06 \\
\hline \multirow[t]{3}{*}{ Experimental } & Male & 14.18 & 2.61 & 19.64 & 2.16 & 5.46 \\
\hline & Female & 15.23 & 1.82 & 19.86 & 1.81 & 4.63 \\
\hline & Total & 14.64 & 2.34 & 19.74 & 2.00 & 5.10 \\
\hline \multirow[t]{3}{*}{ Overall } & Male & 14.66 & 2.65 & 17.82 & 3.08 & 3.16 \\
\hline & Female & 14.88 & 2.54 & 17.88 & 3.33 & 3.00 \\
\hline & Total & 14.77 & 2.58 & 17.85 & 3.19 & 3.08 \\
\hline
\end{tabular}


Table 3. Result of repeated measure ANOVA for Mean pre and post- test scores on total competency scores of male and female in experimental and control groups (within and between subject affects)

\begin{tabular}{|l|r|r|r|r|r|}
\hline \multicolumn{1}{|c|}{ Source } & $\begin{array}{r}\text { Sum of } \\
\text { Squares }\end{array}$ & $\mathrm{df}$ & $\begin{array}{r}\text { Mean } \\
\text { Square }\end{array}$ & F value & P value \\
\hline Within subject effects & & & & & \\
Change & 205.038 & 1 & 205.038 & 140.782 & .000 \\
Change * Group & 1.338 & 1 & 1.338 & .919 & .340 \\
Change * Gender & 16.505 & 1 & 16.505 & 11.333 & .001 \\
Change* Group *Gender & 139.817 & 96 & 1.456 & .000 \\
Error (change) & 160.157 & 1 & 160.157 & 13.489 & .000 \\
Between subject effects & 6.257 & 1 & 6.257 & .527 & .470 \\
Groups & 3.820 & 1 & 3.820 & .322 & .572 \\
Gender & 1139.823 & 96 & 11.873 & & \\
Group * Gender & & & & \\
Error & & & & \\
\hline
\end{tabular}

Note: change refers to different between pre to post sessions irrespective of the groups ( $E$ and $C$ )

Change * treatment refers to different between pre to post sessions for $E$ and $C$ groups (differential gains).

In the pretest on the whole irrespective of the group the total mean pre-scores were 14.77 which increased 17.85. The gain of 3.08 scores was found to be statistically significant where as observed ' $F$ ' value of 306.673 was found to be significant at 0.000 level. Further when change in the scores were verified against control and experimental groups again we find a significant ' $F$ ' value of $140.782(P=0.000)$. From the mean values and gain scores it is clear that the control group has gained a mean of 1.06 scores (pre $=14.9$; post $=15.96$ ) where as experimental group has gained 5.10 scores (pre $=14.64$; post $=19.74$ ). The substantial gain by experimental group can be attributed for effectiveness of diagnostic based remediation programmes. 
Gender wise no significant effect was observed as observed ' $F$ ' value of 0.919 fail to reach significance level criterion. Lastly the gain in the scores with respect to gender and groups was found to be significant $(F=11.333 ; P=0.001)$ where we find that male subjects of experimental group have gained maximum (mean gain $=5.46$ ) and males in the control group gained least (mean gain $=0.23$ ) In between subject effects only between experimental and control group significant difference was observed $(F=13.489 ; P=0.000)$. Gender wise comparison and interaction between gender and groups were found to be non significant.

\section{DISCUSSION}

\section{Main findings of the present study are}

1. Experimental group had gained significantly higher competencies in total scores than the control group. Further, male students of experimental group had substantial gain compared to all other groups.

The substantial gain by experimental group over control group can be attributed for effectiveness of diagnostic based remediation programmes. Hence hypothesis 6 formulated as "There would be no significant effect of diagnostic based remediation programme in improving the proportions of students mastering each competency (percentage of competency mastered) by the group of $V$ standard students in the selected (experimental) schools of Shimoga District" is rejected

Several studies have been conducted in India and abroad relating to the effectiveness of various strategies of teaching mathematics and remedial programmes designed in many ways by researchers. Gusky and Gates (1986) surveyed 46 research studies relating to the effectiveness of blooms mastery learning approach and found that in most of the studies mastery learning approach was beneficial. It is significant to note the positive effects of this approach were more in language and arts than in mathematics and science.

Airasian (1967) and Colins (1969) found that the mastery learning approach was better than conventional method of teaching. Similarly Reese(1976) reported positive effectiveness of remedial teaching over conventional teaching in learning algebra. Block (1970), Reed (1993), Kersh (1990), Meverrech (1986), Kulik et al (1990) have reported beneficial effects of mastery in learning approach on learning mathematics.

In India also several studies have conducted on the effectiveness of several kinds of intervention programmes. Archana Srivastava (2004) study showed better 
achievement level on the part of students with mathematical disability after teaching them with the help of remedial programme. Sullivan(1987) found in his study that students who were thought through mastery learning method scored significantly higher in mathematics than students taught through traditional method. Kumar ,Surinder,Susma and Harizuka(1996) found significant difference between experimental and control groups after teaching mathematics through cooperative learning. They found positive interaction among students. Amruthavalli Devi(2008) studied the effectiveness of strategy of teaching mathematics developed by her based on Piaget and Vigotski's views. She found significant difference between pretest and posttest scores in all the four variables studied namely mathematical thinking, creative thinking, intelligence and mathematics achievement. The above studies have shown positive effect of well designed intervention programme (including remedial programmes and new teaching strategies like discovery method, cooperative teaching, etc)

Rastogi (1983) attempted a study on diagnosis of weaknesses in arithmetic as related to the basic arithmetic skills and their remedial measures and he revealed that basic arithmetic skills could very quickly and conveniently be mastered through the course of self-help in basic arithmetic skills as developed during the study. Vyas (1983) attempted a study on development of symbol picture logic programme and to study its effect on mathematics achievement the students of the experimental group who were given a treatment of the SPLP showed better achievement in mathematics than the control group students. Yadav (1984) found that. After the experimental treatment, the experimental group of pupils exhibited a significantly higher achievement in mathematics than the control group of pupils and higher gain scores of achievement in mathematics and different per-centile achievement scores of the experimental group of pupils were found to be significantly higher than those of the control group of pupils at post-test stage. Das and Barua (1986) studied on effect of remedial teaching in arithmetic among grade IV pupils and they revealed that the major conclusion of the study was that remedial teaching had definitely improved significantly the achievements in arithmetic. Dutta (1986) attempted on learning disabilities in the reasoning power of the students in geometrydiagnosis and prevention and he found that the experimental groups taught by audio-visual materials and techniques achieved significantly more than the controlled groups taught by conventional methods.

In the present study also the experimental group gained significantly higher competencies in total scores than the control group, Male students of experimental group gained most. With long term use of manipulatives in mathematics, educators have found that students make gains in the following general areas (Heddens, piccioto, 1998; Sebesta and martin, 2004). 
- Verbalizing mathematical thinking

- Discussing mathematical ideas and concepts

- Relating real world situations to mathematical symbolism

- Working collaboratively

- Thinking divergently to find a variety of ways to solve problems

- Expression problems and solutions using a variety of mathematical symbols

- Making presentations

- Taking ownership of their learning experiences

- Gaining confidence in their abilities to find solutions to mathematical problems using methods that they come up with themselves without relying on directions from the teacher

The use of manipulates helps students hone their mathematical thinking skills . According to stein and Bovalino(2001), "Manipulatives can be important tools in helping students to think and reason in more meaningful ways. By giving students concrete ways to compare and operate on quantities, such manipulatives as pattern blocks, tiles and cubes can contribute to the development of well grounded, interconnected understandings of mathematical ideas.

Studies have shown that students using manipulatives in specific mathematical subjects are more likely to achieve success than students who don't have the opportunity to work with manipulatives. Following are some specific areas in which research shows manipulatives are especially helpful:

Counting some children need to use manipulatives to learn to count (Clements, 1999)

Place Value Using manipulatives increases students' understanding of place value (Phillips, 1989).

Computation Students learning computational skills tend to master and retain these skills more fully when manipulatives are used as part of their instruction ( Carroll and Porter, 1997). 
Problem Solving Using manipulatives has been shown to help students reduce errors and increase theur scores on tests that require them to solve problems( Carroll and Porter, 1997, Clements, 1999; Krach 1998)

Fractions students who have appropriative manipulatives to help them learn fractions outperform students who rely only on textbooks when tested on these concepts (Jordon, Miller, and Mercer, 1998; Sebesta and martin , 2004).

Ratios/Percentages Students who have approprate manipulatives to help them learn fractions also have significantly improved acheivement when tested on ratios when compared to students who do not have exposure to these manipulatives(Jordon, Miller, and Mercer, 1998)

Manipulatives have also been shown to provide a strong foundation for students mastering the following mathematical concepts (The Access Center, October 1,2004)

- Number relations

- Measurement

- Decimals

- Number bases

- Percentages

Well-known math educator Marilyn burns considers manipulatives essential for teaching math to students of all levels. She finds that manipulatives help make math concepts accessible to almost all learners, while at the same time offering ample opportunities to challenge students who catch on quickly to the concepts being taught. Research indicates that using manipulatives is especially useful for teaching low acheivers(Marsh and Cooke, 1996; ruzic and O'connell, 2001)

Reseach also indicates that using manipulatives helps improve the environment in math classrooms. When students work with manipulatives and then are given a chance to reflect on their experiences, not only is mathematical learning enhanced , math anxiety is greatly reduced(Cain-Caston, 1996; heuser, 2000). Exploring manipulatives, especially self directed exploration, provides an exciting classroom environment and promotes in students possitive attitude towards learning (Heuser, 1999; Moch, 2001). Among the benefits several researchers found for using manipulatives was that they helped make learning fun . (Moch , 2001; Smith et.al, 1999). 
The above studies showed that the improvement of mastery level in the total competencies is due to the use of adequate manipulatives.so in the present study also investigator used adequate manipulatives wherever necessary in his intervention programme. Hence it can be stated that the adequate use of manipulatives can improve the mastery level in attainment of the above competencies.

\section{References}

Amruthavalli Devi,A.(2007), A Study of Cognitive acceleration in mathematics education among primary school children, PhD. Theses, Sri Padmavathi Mahila Vishwavidyanilayam, Tirupathi.

Block, J.H. (1970), The Effects of Various Levels of Performance on Selected Cognitive. Affective, and Time Variables. Unpublished doctoral Dissertation, University of Chicago.

Caine-castone, M(1996). Manipulative queen,Journal of Instructional Psychology,23(4):270274.

Carrol,W.M. and Porter,D(1997). Invented strategies can Develop meaningful mathematical Procedure, Teaching Children Mathematics,3(7), 370-374.

Clements, D.H(1999). "Concrete" Manipulatives,concrete ideas, Contemporary issues in early childhood, 1(1),45-60.

Coronbach, L.J.(1954). Educational Psychology. New York, Horcourt, Brace Javanovich.

Das, R.C. and Barua, A.P.( 1986), Effect of Remedial Teaching in Arithmetic, A Study with Grade IV Pupils, SIE, Assam.

Dutta, A. (1986), Learning Disabilities in the Reasoning Power of the Students in GeometryDiagnosis and Prevention, Ph.D. Edu., Kai. U.

E1-Far lbrahim, A.W. (1982), An Experimental Study of Effect of Using Diagnostic / Perscirptive Procedure on the Mastery Learning of the First Year Algebra Course required of Preservice Secondary School Teachers in Egypt. Proquest Dissertation Abstract, 41/10, 983.

Garrett, H.E. (1986). Statistics in Psychology and Education, Vakils Feffer and Simons Ltd., Bombay

Guskey, T., \& Gates, S. (1988), Synthesis of Research on the Effects of Mastery Learning in Elementary and Secondary Classrooms. Educational Leadership, 43(8), 73-80.

Heddens,J.W(1986).Bridging the gap between the concrete and the abstract, The Arithmetic Teacher,33;14-17.

Heuser,D(1999). Reflections on Teacher philosophies and teaching strategies upon childrens cognitive structure development-Reflection II,Pennsylvania State University, accessed at : .http://www.edu.psu.edu/ci/journals/AETS/heuser.tf.

Jorder,I.,Miller,M. and Mercer,C.D.(1998). The effects of concrete to semiconcret to abstract instruction in the acquisition and retention of fraction concepts and skills. Learning disabilities: A Multidisciplinary Journal,9,115-122. 
Kashinath,H.M.(2005), Construction and validation of battery of tests in mathematics for II,V and VII standard based on KSQAO Competencies. Report of Karnataka School Quality assessment organization(KSQAO)Karnataka State Education Examination Board, Bangalore.

Kratch,M(1998). Teaching Fractions Using Manipulatives, Ohio Council of Teachers of Mathematics,37, 16-23.

Marsh,L.G. and cooke, N.L.(1986). The effects of using manipulatives in teaching maths problem solving to students with learning disabilities. Learning Disabilities Research and Practice, $11(1)$ : 58-65

Moch,P.L(2001). Manipulatives work, The Educational forum.

NCERT(2008). Baseline Achievement Survey, Learning Achievement of class $V$ children. New delhi

Pappert, S(1980).Mindstorms, scrantone ,PA:Basic Books.

Phillips,D.G(1989). The Development of Logical Thinking: A Three year Longitudinal Study, paper presented to the National Council of Teachers of Mathematics, Orlando,FL.

Rastogi, S. (1983). Diagnosis of weaknesses in arithmetic as related to the basic arithmetic skills and their remedial measures, Unpublished Ph.D. Education, Guwahati University.

Reed, Curtis. (1983), The Effects of Mastery Learning Strategy on Student Cognitive Achievement in High School Basic Drafting Classes. Proquest Dissertation Abstract, 44/03, 691.

Ruzic, $R$ and $O^{\prime}$ Connel, $K(2001)$. Manipulatives, Enhancement Literature Review, accessed at http://www.cast.org/ncac/manipulatives.1666.cfm.

Sebesta,L.M. and Martin,S.R.M. (2004). Fractions: Building a foundation with concrete manipulatives, Illinoise Schools Journal,83(2),3-23.

Smith,N.L.,Babilone,C.and vick,B.J.(1999).In Dumpling Soup: Exploring Kitchen, Culture and Mathematics, Teaching Children Mathematics, 6:148-152.

Sowell,E(1989). Effects of manipulative material in mathematics instruction, Journal for Research in mathematics Education,20: 498-505.

The access center, http://coe.jme.edu/mathvidsr/disabilities.htm (otober 1, 2004).

Yadav, P.S. (1984), Effect of Mastery Learning Strategy on Pupils' Achievement in Mathematics, their Self-concept and Attitude towards Mathematics, Ph.D. Edu., Kur. U.

Picciotto, $H(1988)$. Operation sense, Tool based pedagogi,curricular breadth, a proposal, accessed at http;//ww.picciotto.org.

Clements, D.H. and Battista, M.T(1990). Constructive Learning and Teaching, The Arithmatic Teacher,38: 34-35. 